observed that Archimedes does not give a socalled "statical proof" of any purely geometrical theorem; this would be contrary to Greek ideas of mathematical propriety. But the theorem having suggested itself as probable from mechanical (or other) considerations, strict methods were applied to test it-such, for instance, as the process of "exhaustion." In connection with this exhaustion method it is properly pointed out that the Greeks virtually laid the foundations of the integral calculus, much in the same way as Apollonius, in his "Conics," virtually anticipates the results of modern analytical geometry.

Scattered about the book there are numerous references to Greek discoveries and speculations which are not so well known as they ought to be. Thus Archimedes determined the angular diameter of the sun to a comparatively close degree of accuracy (p. 47); Aristarchus of Samos enunciated the Copernican hypothesis (p. 46); and, of course, all mathematicians of the time assumed the earth to be a sphere, and had a very fair idea of its dimensions.

The book is well printed and attractive in appearance; it is adorned by a frontispiece which is a reduced facsimile of that in Torelli's edition of Archimedes' works. The original is a good example of eighteenth-century copper-plateamusing in one respect, because, although the landscape is put into proper perspective, two mathematical diagrams supposed to be drawn on the sand are drawn in their proper shape in the plane of the paper. The process reproduction appears to be very satisfactory, considering the amount of reduction involved. G. B. M.

\section{Australian Meteorology.}

Australian Meteorology: A Text-book, including Sections on Aviation and Climatology. By Dr. Griffith Taylor. Pp. xi+3r2. (Oxford: At the Clarendon Press, 1920.) Price r2s. 6d. net.

$\mathrm{T}$ HIS text-book of meteorology is written for readers in the southern hemisphere, where, as the author truly points out, European and American text-books are to some extent inapplicable by reason of the fundamental difference in the wind circulation around centres of high and low pressure in the two hemispheres. The examples introduced for purposes of illustration in the present work are mainly drawn from Australian conditions, though the author's wide knowledge of world climatology is also freely used. The 300 or so pages of the book are divided into twenty-six chapters, which cover the practical No. 2665 , VOL. IO6] work at observing stations, as well as the more theoretical aspects of dynamical meteorology and climatology. The author has achieved his object in producing a work which will give the reader of fair intelligence, but without advanced knowledge of mathematics or physics, a good general grounding in the subject. In this connection the pages devoted to pressure gradient and Ferrel's law may be particularly commended. One or two parts are less satisfactory, and in particular the reviewer suggests that in a future edition the chapter devoted to upper-air research might be recast, giving less space to the methods employed, and more to the very important results which have been obtained during the past few years in this field. At the same time, a little more attention might be devoted throughout the book to defining the technical terms used, and to explaining in more detail a few of the less obvious types of diagram, which do not at first glance convey much meaning to the unaccustomed reader.

In chap. xviii. a novel theory is put forward to account for the origin of the tropical lows which form over Australia and drift away to the south-eastward. The theory postulates that domes of warm ascending air are formed over the hottest inland regions in summer, and that the upper north-westerly current, striking these fixed domes, forms gigantic eddies which pass away to the south-eastward, being marked at the surface by a low-pressure centre and of ten by falls of rain. Any theory of the formation of depressions will be received with interest. The one here put forward is certainly not lacking in originality. It is surprising to learn that the words "backing" and "veering" are used in Australia in the sense of turning against and with the sun respectively instead of with the meanings counter-clockwise and clockwise as recommended by the International Meteorological Committee in 1905. In a modern text-book of meteorology one misses any reference to G. I. Taylor's eddy conductivity. In dealing with the diurnal change of wind at the surface and in the lower layers the simple convection theory of Espy is referred to, but no reference is made to the more complete explanation put forward by G. I. Taylor, in which the observed facts are well accounted for on the reasonable assumption of a diurnal variation of " $\mathrm{K}$."

In his preface the author offers a half apology for the roughness of the diagrams with which the book is illustrated, but this seems scarcely necessary, as the numerous figures form one of its most valuable features, being mainly of small size, and yet showing just the details required to illustrate the point under discussion.

J. S. D. 